\title{
HISTÓRIAS EM QUADRINHOS NA EDUCAÇÃO ARTÍSTICA, ENERGÉTICA E AMBIENTAL NO PROEJA
}

\author{
A. C. SOUZA ${ }^{1}$ e A. H. FERRAREZ ${ }^{1}$ \\ ${ }^{1}$ Instituto Federal de Educação, Ciência e Tecnologia Fluminense \\ aferrarez@iff.edu.br
}

Submetido 12/01/2017 - Aceito 10/07/2017

DOI: $10.15628 /$ holos.2017.5544

\section{RESUMO}

O PROEJA busca resgatar e reinserir, no sistema escolar regular, jovens e adultos, promovendo uma formação integral na vida e para a vida. A interdisciplinaridade é uma ferramenta para se alcançar uma formação mais humanista. A Arte na Educação cumpre um papel importante na promoção do conhecimento cultural do aluno. Uma das possibilidades de potencializar o aprendizado de arte são as histórias em quadrinhos (HQs) que podem proporcionar excelentes resultados interdisciplinares, sobretudo com a união da linguagem artística e científica. A energia e o acesso a ela são cada vez mais questões centrais no nosso dia a dia. Energia e desenvolvimento são indissociáveis, resultando em forte pressão sobre o meio ambiente. Nesse contexto, a educação energética e ambiental ganha importância e deveria fazer parte da formação de todo brasileiro. Este trabalho teve por objetivo realizar um projeto interdisciplinar envolvendo educação artística, energética e ambiental por meio de histórias em quadrinhos.

PALAVRAS-CHAVE: PROEJA, Educação Artística, Ciência e Tecnologia.

\section{COMICS IN THE ARTS EDUCATION, ENERGETIC AND ENVIRONMENTAL IN PROEJA}

\begin{abstract}
The PROEJA aims to revive and reintegrate in school system, youth and adults by promoting a comprehensive education in life and for life. The interdisciplinarity is a tool to achieve a humanistic education. The Arts in Education has a significant role in promoting the cultural knowledge of the student. One possibility to enhance learning of art are the comics that can deliver excellent results especially united with science language. The
\end{abstract}

energy and access to it are an increasingly central issues in our day-to-day. Energy and development are inseparable resulting in strong pressure on the environment. In this context education energy and environmental gains importance and should be part of the training of every Brazilian. This work aimed to perform an interdisciplinary project involving arts education, energy and the environment through comics.

KEYWORDS: PROEJA; Arts Education, Science and Technology. 


\section{INTRODUÇÃO}

\subsection{Proeja e interdisciplinaridade}

O Programa Nacional de Integração da Educação Profissional com a Educação Básica na Modalidade de Educação de Jovens e Adultos - PROEJA, instituído a partir de 2006, trabalha a formação integrada com o ensino profissionalizante. São percebidas questões em relação ao PROEJA que são marcos na história política brasileira no sentido de promover uma formação integral do indivíduo, na vida e para a vida. O PROEJA busca resgatar e reinserir, no sistema escolar regular brasileiro, jovens e adultos que se encontram afastados do mesmo, devido aos problemas internos e externos à escola, através do acesso à educação geral e, mais especificamente, ao ensino profissional na perspectiva de uma formação integral (Brasil, 2007).

A interdisciplinaridade é uma das ferramentas para se alcançar a formação mais humana, proposta pelo PROEJA. Entende-se por interdisciplinaridade a integração de disciplinas por meio de uma articulação voluntária e a coordenação das ações com vistas a um objetivo comum. A interdisciplinaridade não deve ser considerada como uma meta obsessivamente perseguida no meio educacional simplesmente por força da lei. A interdisciplinaridade deve utilizar os conhecimentos de várias disciplinas para resolver um problema concreto ou compreender um fenômeno sob diferentes pontos de vista. Em suma, a interdisciplinaridade tem uma função instrumental. Trata-se de recorrer a um saber útil e utilizável para responder às questões e aos problemas sociais contemporâneos (Brasil, 2002).

A atitude interdisciplinar consiste em buscar alternativas para conhecer mais e melhor. Atitude de espera ante os atos consumados, atitude de reciprocidade que impele à troca, que impele ao diálogo, atitude de humildade diante da limitação do próprio saber, atitude de perplexidade ante a possibilidade de desvendar novos saberes, atitude de desafio - desafio perante o novo, desafio em redimensionar o velho - atitude de envolvimento e comprometimento com os projetos e com as pessoas neles envolvidas, atitude, pois, de compromisso em construir sempre da melhor forma possível, atitude de responsabilidade, mas, sobretudo, de alegria, de revelação, de encontro, de vida (Fazenda, 1994).

\subsection{Educação artística}

A Arte na Educação vem cumprir um papel significativo e fundamental na promoção do conhecimento da cultura em que o aluno está inserido, aguçando seu senso crítico, agregando ao seu repertório, conhecimentos e habilidades cada vez mais valorizadas na sociedade competitiva em que vivemos, tais como flexibilidade, imaginação, inventividade e criatividade, valores estes que modelam não só o trabalhador apto a exercer as habilidades específicas da profissão, mas um cidadão consciente de sua importância e potencial.

Esse conhecimento de si mesmo, suas emoções, permeados pelo pensamento crítico e construtivo, possibilitados pela apreciação da diversidade de manifestações artísticas e a produção de trabalhos artísticos, são algumas entre várias razões para o ensino de Artes (Mendonça, 2008).

É objeto de reflexão de expressiva parte dos arte-educadores, nos dias atuais, a necessidade de não somente estimular a sensibilidade na percepção da arte, mas permitir ao aluno uma participação ativa e diligente também no processo do fazer, contemplando assim um ensino-aprendizado da arte fundamentado no trinômio apreciação, reflexão e elaboração. 
Dentre as inúmeras possibilidades de contextualizar e potencializar o aprendizado de arte, as histórias em quadrinhos (HQs) se apresentam como uma ferramenta que oferece amplas possibilidades de utilização em sala de aula, devido às características próprias dessa forma de linguagem que reúne artes visuais e literatura, dialoga com as técnicas comuns à fotografia e cinema e, entre os seus muitos predicados, as histórias em quadrinhos são um dos mais difundidos meios de fabulação visual e popular do planeta e, dificilmente, um aluno não tenha, ao menos alguma vez na vida, lido um gibi, como popularmente são chamadas as HQs no Brasil (Patati e Braga, 2006).

As chamadas histórias em quadrinhos se baseia numa ideia simples. A ideia de posicionar uma imagem após a outra para ilustrar a passagem do tempo. Os quadrinhos são um idioma. Seu vocabulário consiste de toda a gama de símbolos visuais, incluindo o poder dos cartuns e do realismo, tanto separadamente como em surpreendentes combinações. O coração dos quadrinhos está no espaço entre um quadro e outro, onde a imaginação do leitor dá vida a imagens inertes (Mccloud, 2005).

A simples leitura em sala de aula, em voz alta, por parte dos alunos, que decifra facilmente os códigos visuais das HQs e tende a representar a carga dramática implícita nos diálogos das personagens, pode ser um excelente recurso para desenvolvimento da oralidade. Quando disponíveis os recursos de projeção de imagens, utilizando quadrinhos digitalizados a partir de dispositivos de captura de imagem, a referida proposta de leitura coletiva de quadrinhos se torna uma experiência muito proveitosa para fins educativos. A identificação dos elementos dessa linguagem, os formatos dos balões, dos requadros, signos cinéticos, onomatopeias e metáforas visuais e até mesmo a percepção da narrativa visual, incluindo os planos e angulações podem ser objeto de análise (Eisner, 1989).

Se, por um lado, a simples leitura e apreciação dos quadrinhos revelam várias possibilidades de utilização com fins pedagógicos; de outro, a produção de quadrinhos por parte dos alunos amplia consideravelmente seu potencial como ferramenta no ensino-aprendizado.

Até mesmo a elaboração de roteiros de histórias em quadrinhos pode ser utilizada como exercícios de avaliação do aprendizado. Uma das possibilidades de utilização do recurso do roteiro em aula pode se dar a partir da utilização de histórias em quadrinhos profissionais para elaboração de roteiros. O aluno pode descrever, em forma de roteiro, todos os detalhes da $\mathrm{HQ}$ como se fosse ele o autor do referido roteiro, procedimento este útil tanto na disciplina de Artes como em Língua Portuguesa (Danton, 2013).

Quanto à possibilidade de estimular e explorar não somente o potencial criativo e artístico dos alunos na criação de histórias, mas na produção dos desenhos necessários à produção de suas próprias histórias em quadrinhos, pode-se crer que desenhar não é privilégio de quem desenha com talento e expertise, assim como quem estuda biologia não é ou será necessariamente um biólogo. A própria escrita é uma espécie de desenho que aprimora com a repetição e se assinamos e escrevemos, somos, no mínimo, bons ou razoáveis desenhistas de letras no qual é impresso nosso estilo pessoal. O desenho artístico pode ser estimulado de várias maneiras na disciplina de Artes, mas os quadrinhos, na modalidade cartum com sua forma estilizada de representação, se apresentam como uma das opções mais fáceis de serem manejadas tanto pelo educador quanto pelo aluno. Partindo de exercícios básicos de desenho e sempre baseadas em geometrização para estruturar os corpos das personagens os alunos podem assimilar princípios de anatomia, proporção, movimento e perspectiva (Edwards, 1979).

Após os exercícios de desenho básico, é possível direcionar a produção dos quadrinhos por parte dos alunos com o tema que for o mais conveniente, desde a criação de histórias que retratem seu cotidiano e de personagens baseados em colegas de sala de aula e situações vividas 
no ambiente escolar ou produzir quadrinhos com temas que dialoguem com outras disciplinas e linguagens.

A linguagem da ciência é a que busca transmitir ideias de natureza científica, técnica ou filosófica. Suas características fundamentais são a objetividade, a ordenação lógica dos elementos racionais. Tem como finalidade informar, instruir.

A linguagem da arte é a que, estilisticamente trabalhada, procura criar um estado psíquico de emoção estética. Suas características fundamentais são a subjetividade, a ordenação intuitiva dos elementos psicológicos. Tem como finalidade o prazer intelectual, a busca de uma verdade psicológica ou o simples entretenimento mental (André, 1982).

É na interdisciplinaridade que os quadrinhos com fins educacionais podem proporcionar excelentes resultados sobretudo ao unir a linguagem da arte à da ciência, otimizando assim a aprendizagem.

\subsection{Educação energética e ambiental}

A energia está presente em todas as nossas ações. A disponibilidade, qualidade e custo da energia precisam ser considerados em todos os projetos do nosso dia a dia, desde um simples planejamento de férias até um plano de governo para vários anos de investimentos. Energia é cada vez mais a questão central nos dias atuais e próximos. $O$ acesso à energia é algo estruturante na nossa sociedade. É de interesse público que os cidadãos tenham esse direito. Existe a indissociabilidade entre energia e desenvolvimento, mas a dinâmica desse relacionamento resulta em forte pressão sobre o meio ambiente, uma vez que o crescimento econômico tem estado atrelado à expansão da oferta de energia. Verifica-se nos últimos tempos o surgimento de uma consciência ambiental o que implica numa maior preocupação com a sustentabilidade energética. Infelizmente essa não é uma preocupação geral da população, nem da maioria dos setores produtivos e políticos (Macedo, 2013).

São consideradas fontes de energia toda substância (petróleo, carvão, urânio, biomassa) que possa produzir energia em processos de transformação (combustão, fissão nuclear) como também as formas de energia (energia solar, gravitacional), associada ou não ao movimento dos corpos, fluidos (energia das ondas, hidráulica) e gases (energia eólica), ou à temperatura das substâncias (energia geotérmica), cuja transformação em outras formas de energia pode ser realizada em larga escala.

As fontes de energia como o petróleo, apesar de serem produzidas naturalmente, levam milhões de anos para serem repostas naturalmente e, mesmo sendo possível a reposição artificial, os custos são exorbitantes e o gasto de energia é igual ou superior a quantidade a ser obtida o que torna o processo inviável. Neste caso essas fontes são chamadas de não renováveis. Já fontes, cuja reconstituição pode ser feita sem grandes dificuldades em alguns anos ou menos, são chamadas de fontes renováveis de energia. São exemplos de fontes renováveis: a energia solar, a energia eólica, a energia hidráulica, a energia da biomassa (lenha, biogás, biodiesel, carvão vegetal, álcool, etc), energia das marés, etc (Silva, 2013).

Muitos especialistas apontam as fontes renováveis de energia como a única solução para suprir um desenvolvimento econômico e ambiental sustentável, e propõem a substituição imediata das fontes não renováveis, com vistas a reduzir os efeitos ambientais e fomentar a transição para um novo perfil de consumo de energia de maneira estável sem escassez ou elevação de preços dos energéticos (Jannuzzi e Swisher, 1997).

Segundo as Nações Unidas, nos últimos anos, o consumo mundial de energia primária proveniente de fontes não renováveis (petróleo, carvão, gás natural e nuclear) correspondeu a aproximadamente $86 \%$ do total, cabendo apenas $14 \%$ às fontes renováveis. Esta grande 
dependência de fontes não renováveis de energia tem tido como consequência, além da preocupação permanente com o esgotamento dessas fontes, a emissão de grandes quantidades de dióxido de carbono $\left(\mathrm{CO}_{2}\right)$ na atmosfera. O teor de dióxido de carbono na atmosfera tem aumentado progressivamente, levando ao aumento da temperatura média da biosfera terrestre, o famigerado aquecimento global (CGEE, 2008).

De acordo com estudo do Painel Intergovernamental de Mudanças Climáticas (IPCC), realizado em 2001, durante o período de 1750 a 1998 a concentração de gases de efeito estufa (GEE) duplicou na atmosfera. Os GEE são aqueles que têm a capacidade de reter a radiação infravermelha (calor) emitida pela Terra, aumentando a temperatura na superfície terrestre e do mar. O aumento da concentração de GEE poderá provocar um aumento médio da temperatura no planeta entre 1,4 e 5,8ㄷ nos próximos cem anos (IPCC, 2001). São considerados gases de efeito estufa o dióxido de carbono $\left(\mathrm{CO}_{2}\right)$, o metano $\left(\mathrm{CH}_{4}\right)$, o óxido nitroso $\left(\mathrm{N}_{2} \mathrm{O}\right)$, o hexafluoreto de enxofre $\left(\mathrm{SF}_{6}\right)$ e as famílias dos perfluorcarbonos que são compostos completamente fluorados como perfluormetano $\left(\mathrm{CF}_{4}\right)$ e perfluoretano $\left(\mathrm{C}_{2} \mathrm{~F}_{6}\right)$ e dos hidrofluorcarbonos (HFCs) (Rocha, 2003).

A Figura 1 mostra como a radiação infravermelha é bloqueada pelos gases de efeito estufa.

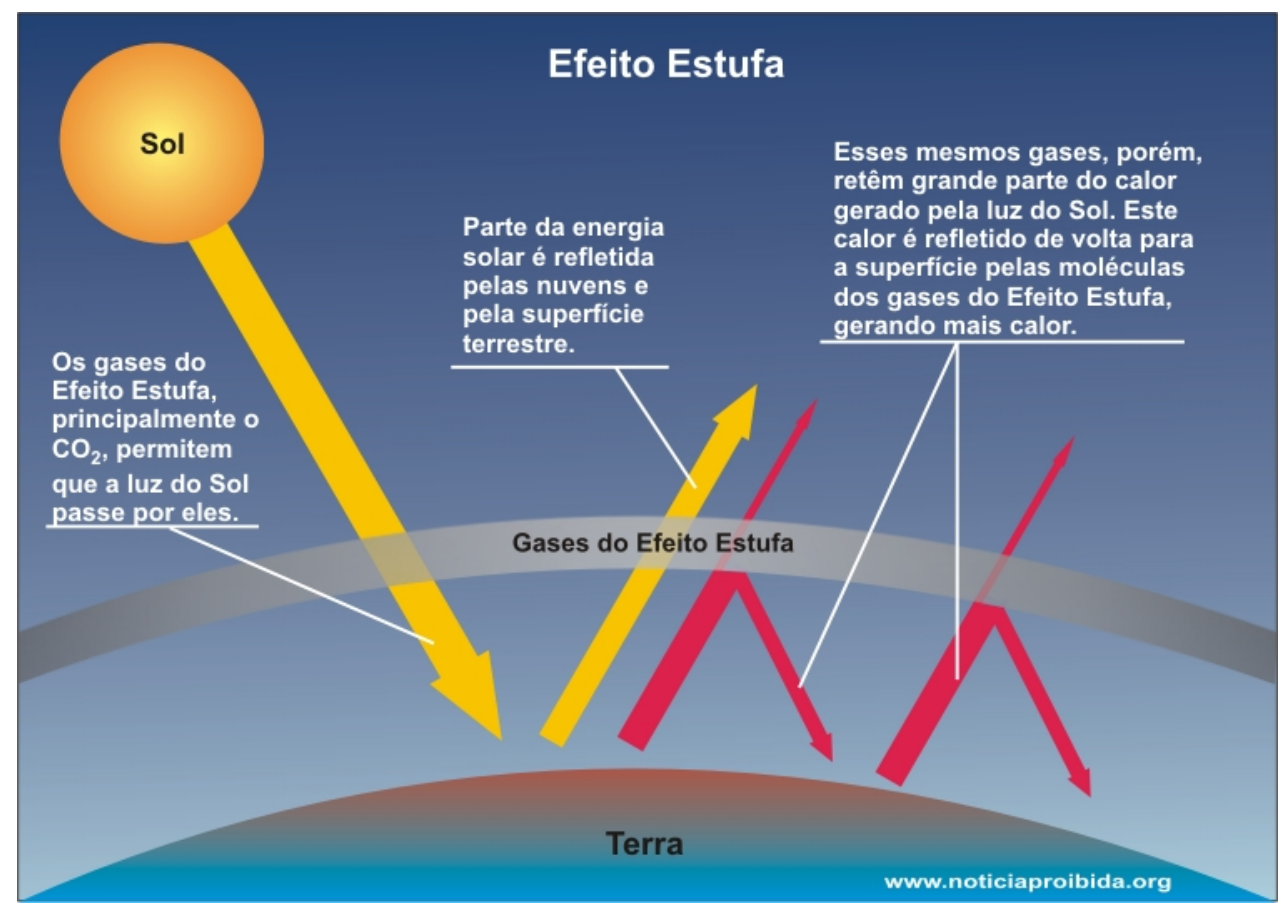

Figura 1 - Esquema do Efeito Estufa

Fonte: (Notícia Proibida, 2010)

O aquecimento global implicará em impactos econômicos, sociais e econômicos que afetarão todos os países. Esses impactos serão diferenciados dependendo da região do mundo (Manfrinato, 1999).

No Quadro 1 são mostradas alguns desses impactos.

Quadro 1 - Região do planeta e impactos provocados pelo aquecimento global

Região Previsão de Impactos

África

i) Diminuição da produção agrícola

ii) Diminuição da disponibilidade de água na região do Mediterrâneo e em países do sul 


\begin{tabular}{ll}
\hline & iii) Aumento dos vetores de diversas doenças \\
iv) Aumento da desertificação \\
v) Extinção de animais e plantas \\
i) Diminuição da produção agrícola \\
ii) Diminuição da disponibilidade de água nas regiões árida e semiárida \\
iii) Aumento do nível do mar deverá deslocar dezenas de milhões de \\
pessoas \\
Austrália e Nova & i) Diminuição da disponibilidade de água \\
Zelândia & ii) Extinção de animais e plantas \\
Europa & i) Desaparecimento de geleiras nos Alpes \\
América Latina & ii) Aumento da produção agrícola em algumas regiões \\
iii) Impactos no turismo \\
i) Diminuição da produção agrícola \\
América do Norte & ii) Aumento dos vetores de diversas doenças \\
iii) Extinção de animais e plantas \\
i) Aumento da produção agrícola em algumas regiões \\
ii) Aumento dos vetores de diversas doenças \\
i) Diminuição da calota polar \\
ii) Extinção de animais e plantas \\
i) Aumento do nível do mar deverá deslocar dezenas de milhões de \\
pessoas \\
ii) Diminuição da disponibilidade de água \\
iii) Diminuição da atividade pesqueira \\
iv) Diminuição no turismo
\end{tabular}

Fonte: (IPCC, 2001).

A educação energética e ambiental deveria fazer parte da formação de todo brasileiro, fornecendo conhecimento da "matriz" de fontes/usos de energia, com informação quantitativa sobre as fontes primárias de energia usadas (petróleo, hidráulica, biomassa, nuclear, etc) sua conversão para formas de energia mais úteis para o uso final (eletricidade, calor, acionamento mecânico, iluminação), as perdas e desperdícios associados, e sua distribuição pelos setores de uso (residencial, industrial, comercial, transportes, etc). Parte dessa formação envolveria introduzir os princípios da termodinâmica, o entendimento das conversões de energia, evolução, causas e consequências do uso da energia, o fim da era do petróleo e aquecimento global.

Este trabalho teve por objetivo realizar um projeto interdisciplinar envolvendo educação artística, energética e ambiental por meio de histórias em quadrinhos.

\section{MATERIAL E MÉTODOS}

Este trabalho foi realizado no Instituto Federal Fluminense, campus Itaperuna, numa turma do módulo I do Curso Técnico de Eletrotécnica, Modalidade PROEJA. Foi proposto à turma que o trabalho final da disciplina "Artes" fosse a produção de uma "tirinha" que abordasse o tema: "Energias Alternativas e Sustentabilidade". Foi ministrada uma palestra para a turma com vistas a introduzir o tema. Foram levantadas várias bibliografias sobre o assunto e realizadas várias consultas à internet. As aulas de Artes se transformaram em laboratório de ideias. Para 
minimizar as dificuldades e limitações quanto à produção dos desenhos ou histórias foi facultada a formação de grupos de dois alunos. A interação e a cooperação entre os componentes dos grupos foram facilitadas pela distribuição das diversas tarefas envolvidas na produção das tirinhas: pesquisa, roteiro, esboço, desenho, finalização à tinta, digitalização, colorização, letreiramento. Primeiramente foi feito um esboço em papel do que seria a história em quadrinhos, a seguir esse desenho foi finalizado a nanquim para, posteriormente, ser digitalizado em scanner. Uma vez obtidos os arquivos digitais, a colorização e o letreiramento foram feitos utilizando as ferramentas digitais. Assim os alunos puderam também se familiarizar com o computador e manejar de forma conjugada arte e tecnologia.

\section{RESULTADOS E DISCUSSÃO}

As tirinhas produzidas são apresentadas a seguir com os comentários respectivos, considerando os aspectos energéticos, ambientais e artísticos:

\section{Trabalho 1:}

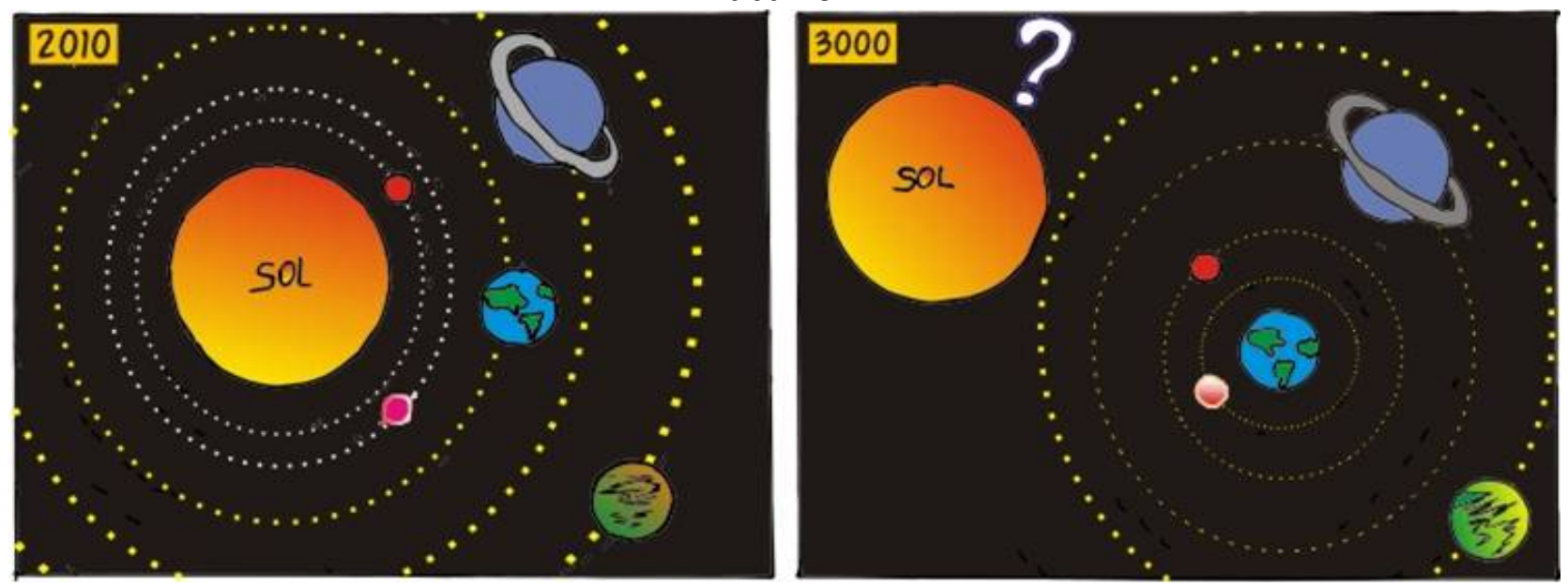

Alunos: George da Silva Vicente e Wellington da Silva Faria

Comentário: Em 2010 tem-se o Sistema Heliocêntrico assim como defendido por Nicolau Copérnico. O Sol é a fonte de energia térmica, e a Terra é o terceiro planeta mais próximo do Sol. A vida na Terra só se tornou possível devido ao fato de não sermos tão quentes como Vênus e nem tão frios como Marte. Em 3000, o Sistema passa a ser Geocêntrico. Será que isso tem a ver com o aumento da temperatura da Terra devido ao aquecimento global? Uma mostra simples de história sem personagens humanos ou antropomorfizados. É possível fazer quadrinhos com tudo e sobre absolutamente tudo. O que vale é a criatividade. As elipses em linhas descontínuas, representando a órbita dos planetas, são uma variação dos elementos típicos da linguagem dos quadrinhos chamados de linhas cinéticas e que figuram como um reforço expressivo na ideia do movimento de deslocamento do núcleo orbital. 
Trabalho 2:
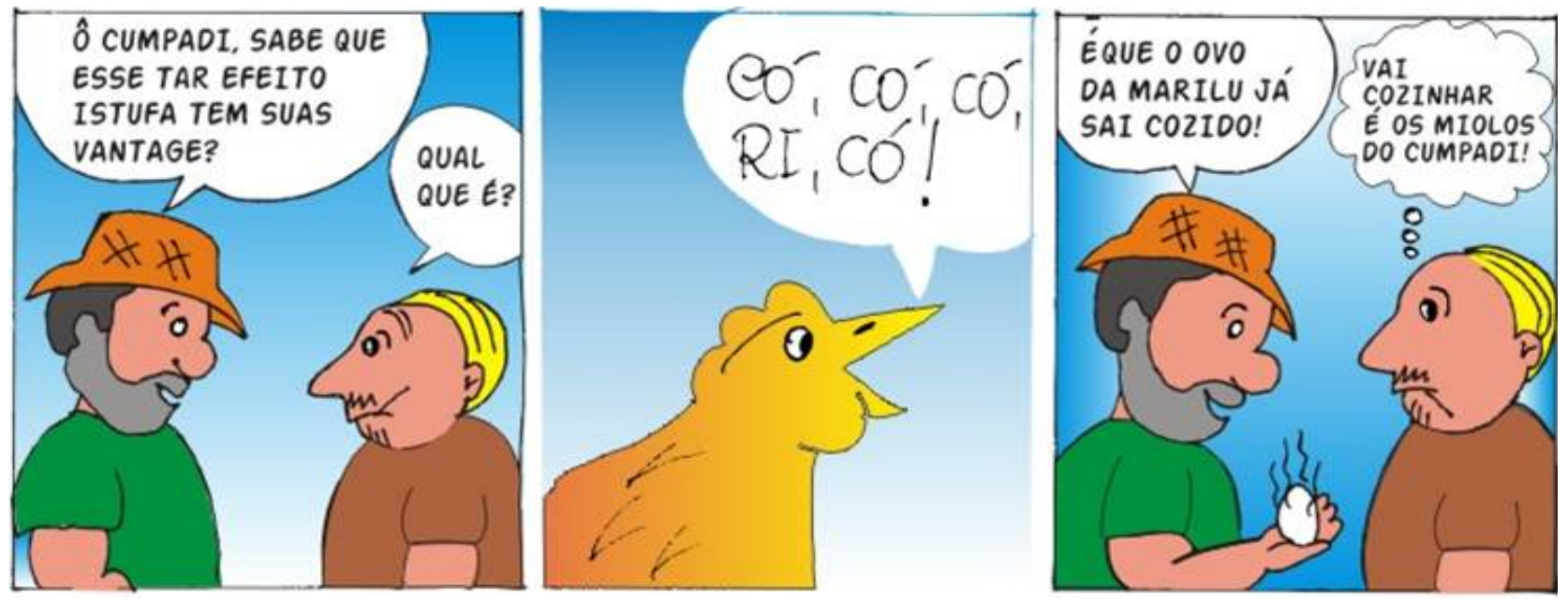

Aluno: Marco Antônio Braga Pimentel

Comentário: Devido ao aumento da temperatura média na superfície da Terra, galinhas como a Marilu já botam ovos cozidos. Destaque para os diálogos em linguagem coloquial, que tornam mais verossímeis as personagens. A estilização do chapéu de palha ganha uma caracterização facilmente reconhecível, bastando apenas três linhas para sugerir a trama da fibra vegetal. Exemplo de como os alunos podem dispor dos elementos da gramática visual na prática e com espontaneidade, sejam linhas, pontos, volumes, etc. O requadro central não apresenta contorno e destaca uma onomatopeia, dando ritmo e enriquecendo a narrativa. Junto com as onomatopeias e recordatórios ou legendas, os balões são os elementos textuais dos quadrinhos. No exemplo acima, o balão-pensamento, em forma de nuvem, é um dos muitos formatos de balão. Na grande maioria dos casos, os balões, que funcionam como contenedores dos textos, possuem um elemento identificador do interlocutor, apontando para o personagem donde se origina a respectiva fala, chamado de delta ou rabicho. O rabicho varia segundo o estilo do balão. No último quadro, por exemplo, o balão-pensamento possui um rabicho em forma volatizada ou esfumaçada. Vale lembrar que, na Itália, os quadrinhos são chamados de "fumetti" numa alusão à forma dos balões, que se assemelham a fumaças que pairam sobre os personagens das HQ. Vale ainda destacar as linhas térmicas que emanam do ovo cozido no último quadro, indicando um bom domínio da linguagem por parte do autor. 
Trabalho 3:

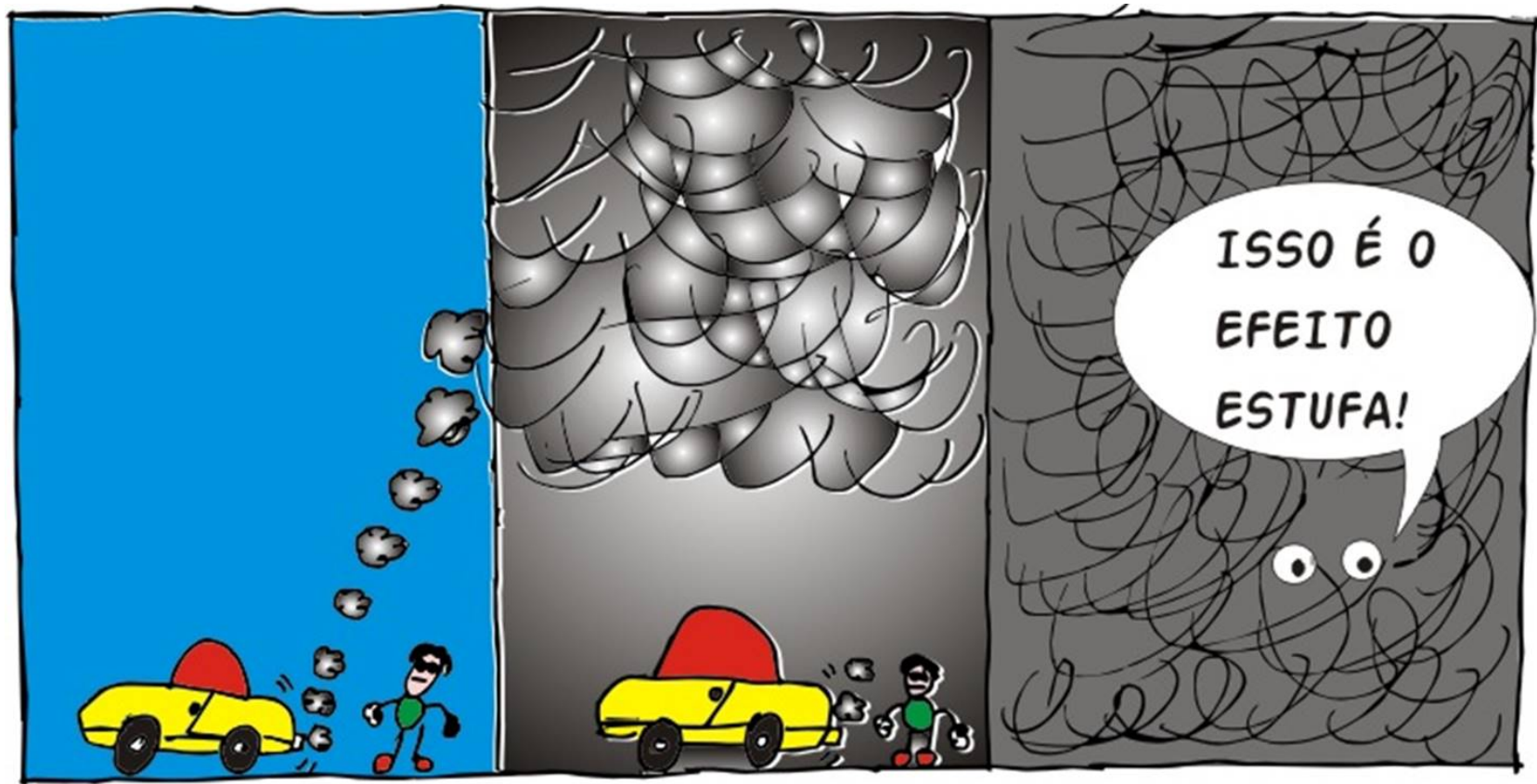

Aluno: Thiago Ferreira de Queiroz

Comentário: Veículos movidos a combustíveis fósseis como gasolina e óleo diesel emitem uma grande quantidade de gases de efeito estufa (GEF) como o $\mathrm{CO}_{2}$ (Dióxido de Carbono), $\mathrm{CH}_{4}$ (Metano) e $\mathrm{N}_{2} \mathrm{O}$ (Óxido Nitroso). Nessa tirinha é perceptível o pouco domínio do desenho por parte do autor, mas, durante as etapas da produção da tira cômica, houve uma boa apropriação dos recursos visuais disponíveis, nas cores utilizadas e, principalmente, ao valer-se de uma metalinguagem, ao usar o espaço gráfico dos requadros para exemplificar o acúmulo crescente dos gases tóxicos no efeito estufa, tal como ocorre em escala planetária. 
Trabalho 4:

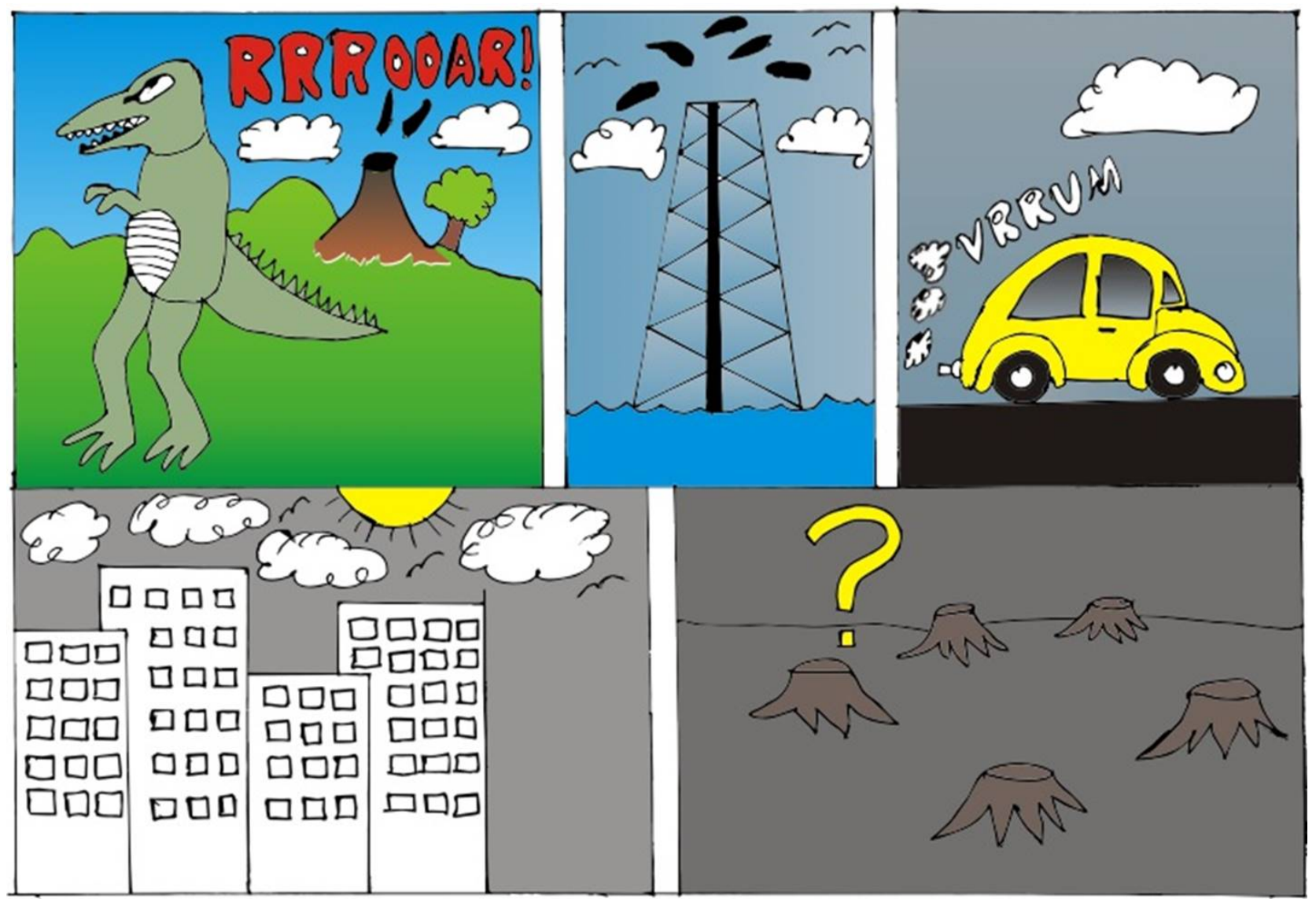

Alunos: Carlindo Carlos Torres Coelho e Josias Mattos do Valle

Comentário: Observa-se um ciclo histórico-energético em nosso planeta. Primeiramente vê-se um dinossauro (seria um T-Rex?) num ambiente primitivo. Os restos mortais desse dinossauro após muitos e muitos anos submetidos à alta pressão e temperatura se transformam em petróleo. O homem consome esse petróleo em um tempo muito menor do que o necessário para sua formação (isso faz do petróleo uma fonte não renovável de energia). A queima desse combustível implica em poluição e junto com ações não sustentáveis a devastação ambiental. Há uma criativa utilização de recursos narrativos para representar um processo gradativo de extinção da vida, culminando com a natureza totalmente devastada. As onomatopeias e a interrogação no último quadro são os únicos elementos textuais que reforçam a leitura, que, independente de códigos verbais, é de fácil entendimento por parte do leitor. 


\section{Trabalho 5:}
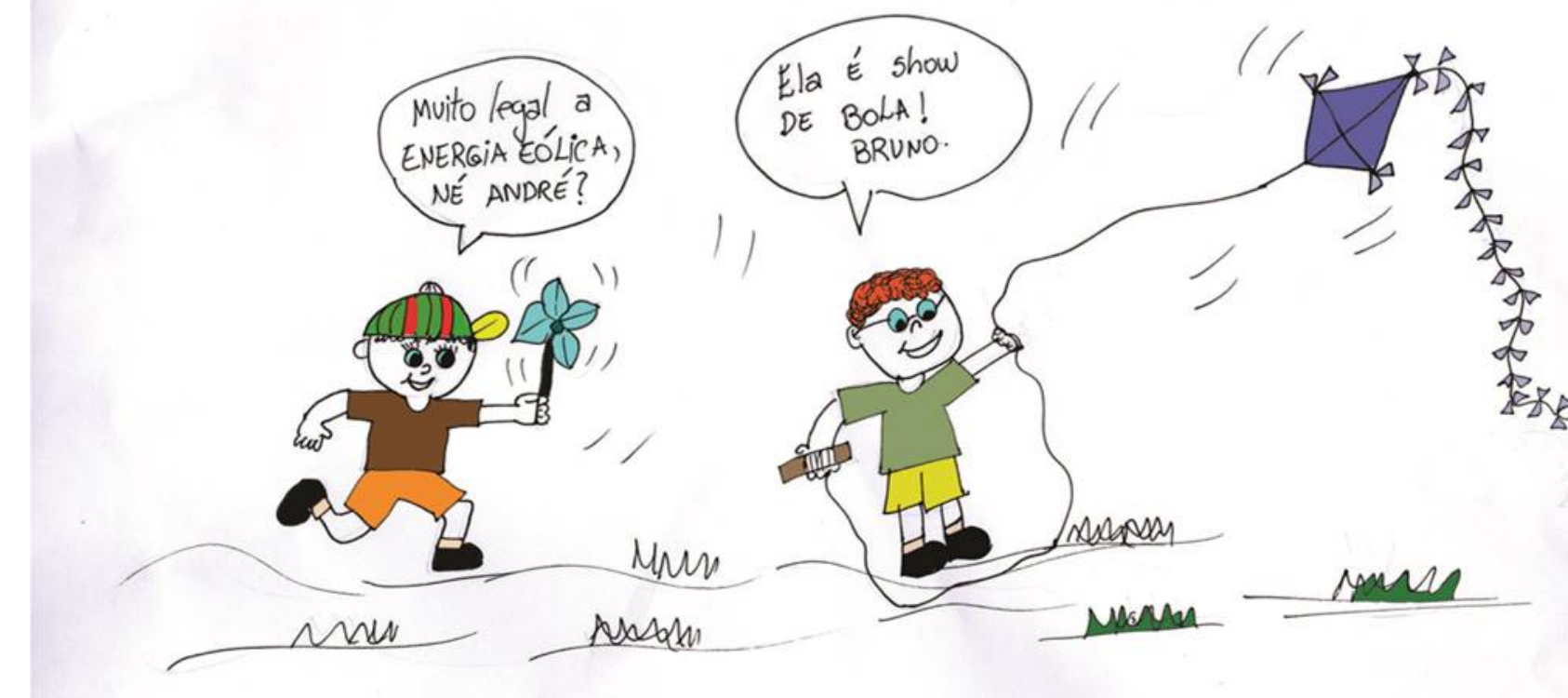

Aluno: Elson Pereira da Silva

Comentário: O potencial eólico brasileiro estimado é de $350 \mathrm{GW}$ de capacidade instalada e uma geração de 920 TWh/ano (CEPEL, 2010). O consumo total de energia elétrica no Brasil em 2011 foi de 472 TWh (EPE, 2012). O quadrinho acima mostra que, desde pequenos, utilizamos desse enorme potencial de energia para realizar as nossas brincadeiras. A utilização dos recursos do software utilizado para finalização dos quadrinhos, tais como filtros e cores em dègradé, foi um elemento motivacional no processo criativo. No entanto, como no exemplo acima, alguns alunos dispensaram o uso dos recursos digitais para o letreiramento, mantendo sua caligrafia original, no intuito de imprimir personalidade ao trabalho. Os diálogos em linguagem coloquial e o traço estilizado também são destaques. 
Trabalho 6:

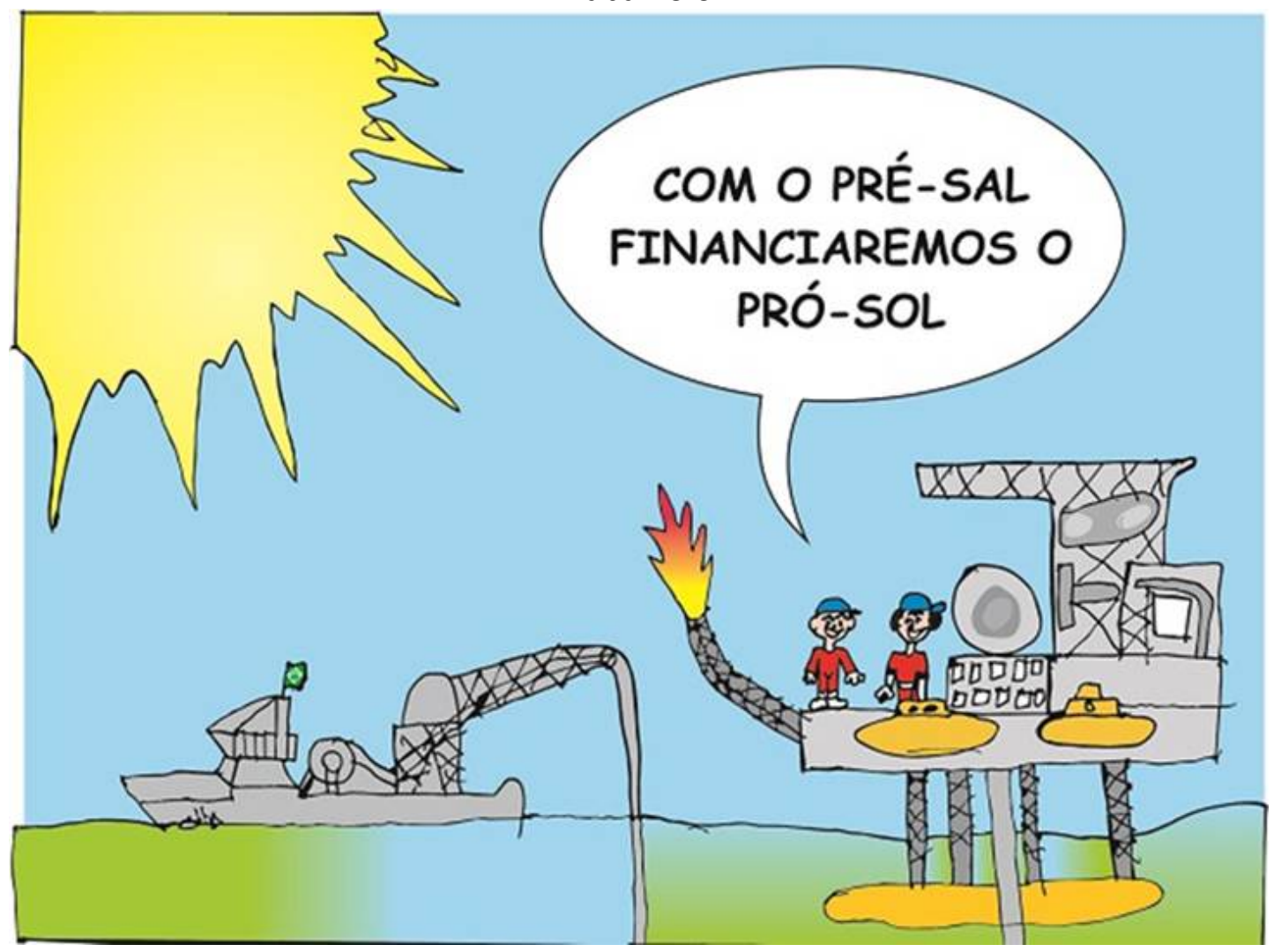

Aluno: Adriano Barbosa Loureiro Ferreira

Comentário: De acordo com estudos da Petrobrás a previsão é de que em 2020 a produção de petróleo do Pré-Sal seja de 1,8 milhão de barris por dia. A exploração dessa riqueza poderá representar grandes oportunidades para o povo brasileiro desde que o ritmo de exploração dessas reservas não seja o das grandes potências mundiais de petróleo (Estados Unidos e China). O quadrinho apresenta mais uma alternativa para aplicação dos recursos do Pré-Sal, além da educação, que é investir no desenvolvimento de novas tecnologias de aproveitamento das energias renováveis. Na linguagem do humor gráfico é muito comum o uso de um traço estilizado, quase "caligráfico", o que não prejudica a legibilidade da informação, pelo contrário, se ajusta perfeitamente à mensagem direta e sucinta. 
Trabalho 7:
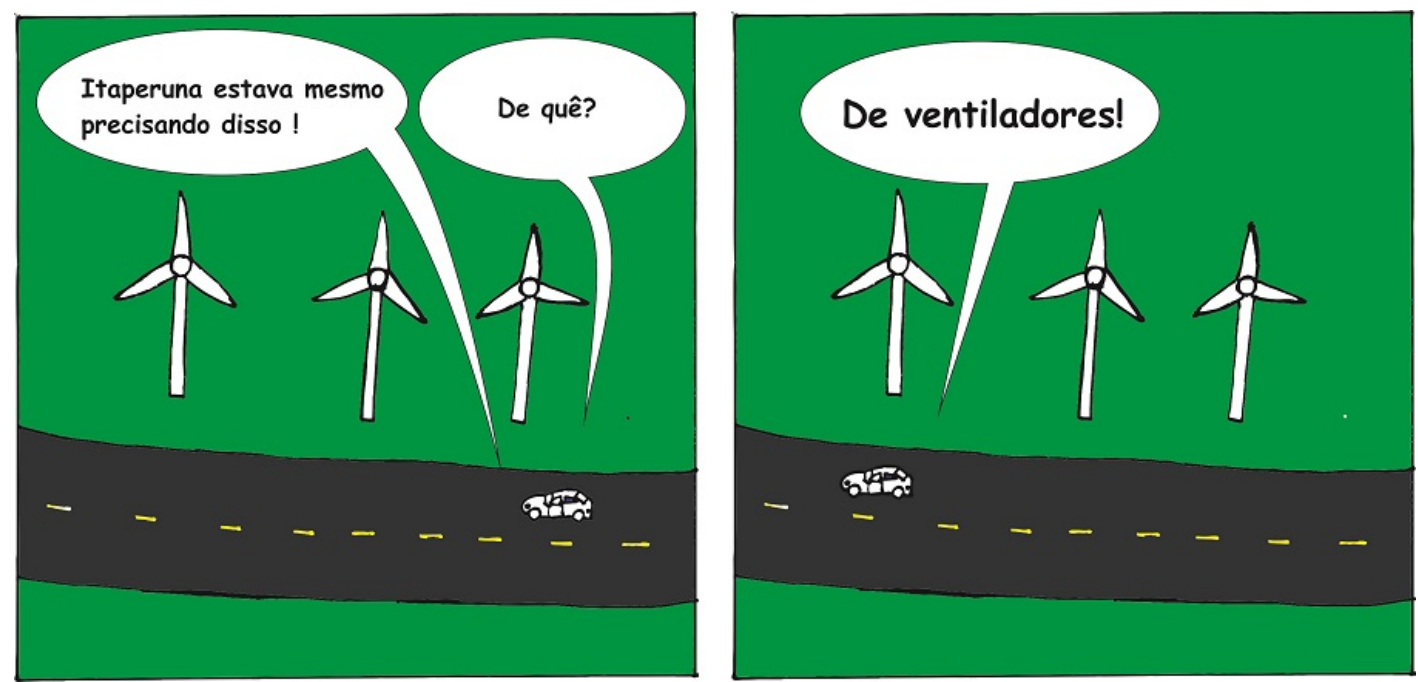

Aluno: Reinaldo de Paulo Bartholazi

Comentário: Alusão à energia eólica e aos aerogeradores como ventiladores para amenizar a temperatura escaldante da cidade de Itaperuna/RJ que pode chegar aos 40 ㅇ. . A ironia presente na cena é um recurso comumente presente no humor gráfico, que usa analogias e trocadilho visual, constituindo-se na "alma do cartum". A criatividade, ao extrair graça do tema abordado, valoriza o traço simples do autor.

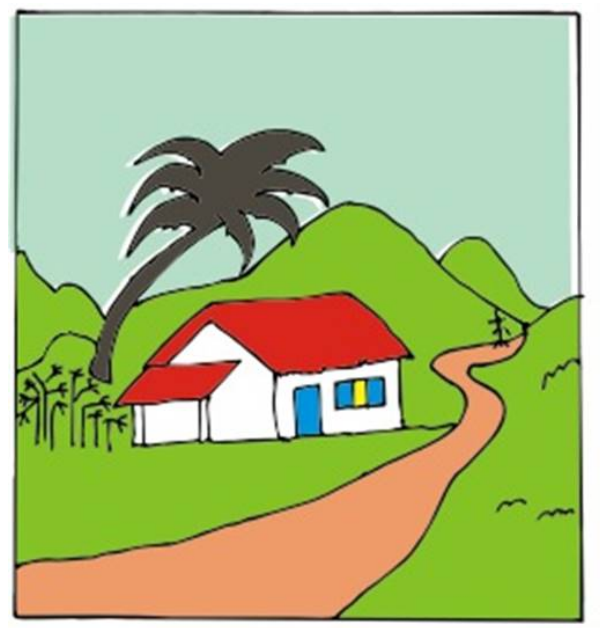

Trabalho 8:
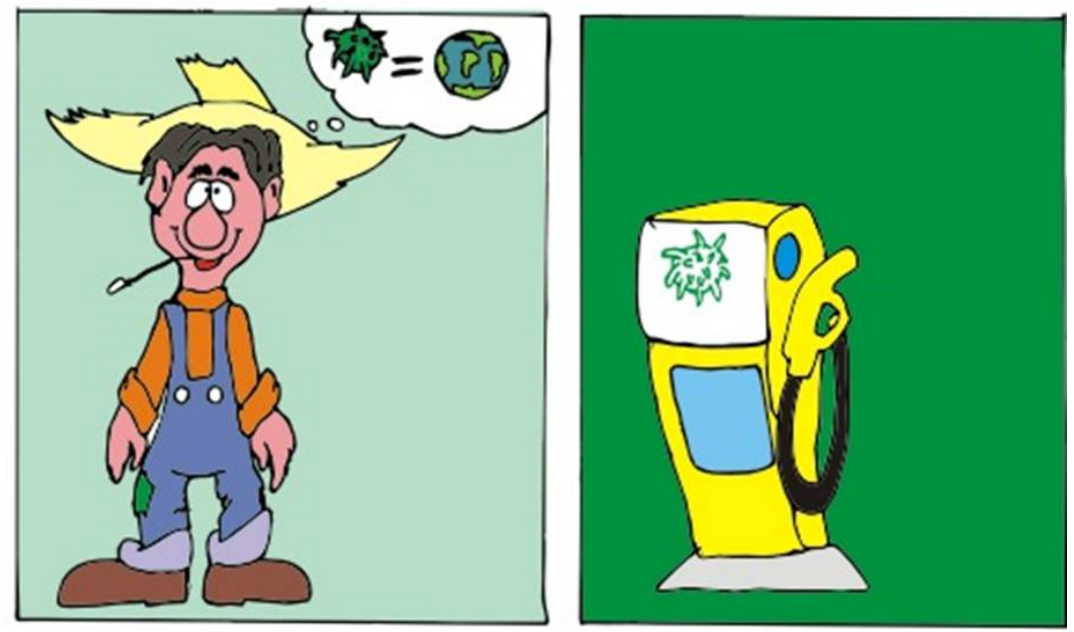

Aluno: Paulo Ferreira de Souza

Comentário: A agroenergia é uma alternativa energética que pode contribuir para a mitigação do efeito estufa. A mamona, planta oleaginosa, pode ser a base do biodiesel - combustível obtido a partir de matérias-primas vegetais ou animais. O biodiesel pode substituir o óleo diesel e tem a vantagem de ser menos poluente e renovável. O aluno autor da tirinha acima, que apresentou um dos melhores resultados na qualidade do traço, optou por uma mensagem desprovida de texto, mas rica em significados e expressividade. 
Trabalho 9:

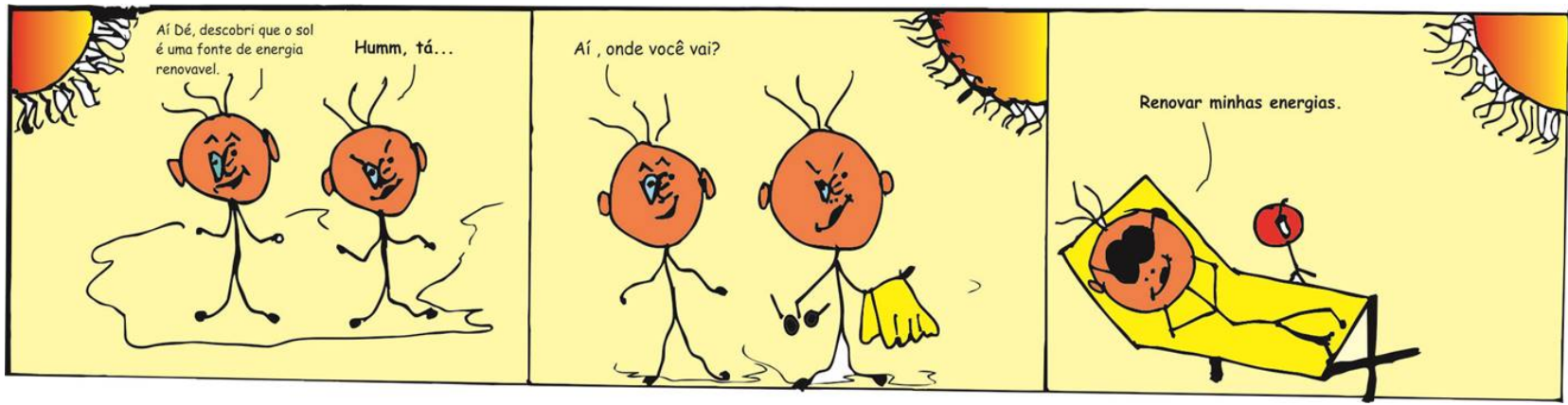

Aluno: Igor Pizane da Silva e Carlos Rubens Rios Rodrigues

Comentário: A energia proveniente do Sol é muito generosa com o Brasil. O país possui uma irradiação média anual que varia entre 1200 e $2400 \mathrm{kWh} / \mathrm{m}^{2}$ (EPE, 2012). Esse valor é superior à irradiação da Alemanha, França e Espanha onde a geração fotovoltaica é bastante difundida. $O$ personagem do quadrinho está renovando suas energias com a mais abundante fonte renovável que temos à nossa disposição. O efeito humorístico presente na fala e ações dos personagens junto com o elemento surpresa no argumento da tirinha é chamado nos comics de "gag" e pode ser definido como "piada rápida". Esse conteúdo humorístico amplia o valor autoral do trabalho. A "gag" normalmente faz rir e pensar, permitindo ao leitor ampliar o debate sobre o tema em questão.
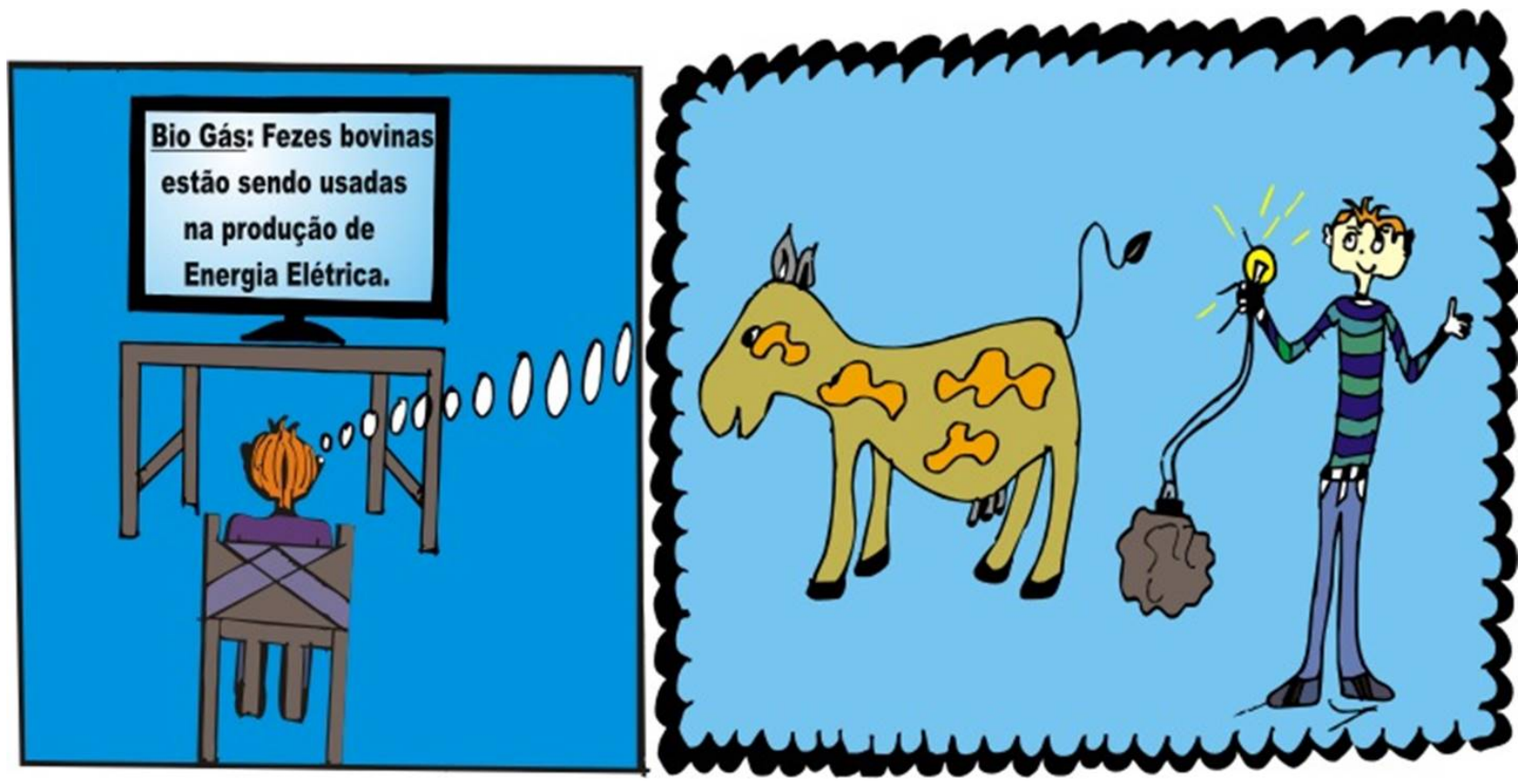

Aluno: Robson Nascimento Rodrigues

Comentário: O biogás é um combustível relativamente barato. É encontrado em qualquer unidade de acúmulo de resíduos urbanos ou agroindustriais. Surge da biodigestão anaeróbia, processo microbiológico em que bactérias convertem a matéria orgânica em biogás. Tem na sua composição metano $\left(\mathrm{CH}_{4}\right)$, dióxido de carbono $\left(\mathrm{CO}_{2}\right)$, hidrogênio $\left(\mathrm{H}_{2}\right)$, e outros gases. Por meio da conversão energética, utilizando motores de combustão interna ou microturbinas, pode ser transformado em energia elétrica. Aqui uma inovação do aluno, ao usar um balão-pensamento 
fora do requadro em que se encontra o personagem autor do pensamento em questão. Em proporção idêntica ao primeiro quadro e disposta à direita deste, passa a ter a função de quadrinho. Na linguagem das HQs, normalmente um quadrinho com a forma de nuvem é utilizada para flash-backs, rememorações de fatos. No entanto, fica a dúvida, diante da criativa solução apresentada pelo aluno: o pensamento é uma imaginação ou ideia evocada pela informação recebida, ou a lembrança de um experimento já feito e bem sucedido que ratifica a notícia da TV?

\section{CONCLUSÃO}

Os resultados alcançados demonstram que a proposta de abordar de forma interdisciplinar o tema "Energias Renováveis e Sustentabilidade" foi alcançada. As tirinhas cumpriram o papel de síntese, na aplicação dos conhecimentos manejados. A junção de palavras e imagens nas histórias em quadrinhos foi eficaz na fixação dos conceitos. Desde o processo de pesquisa em que os alunos foram estimulados a fazer uma imersão no tema proposto, através de pesquisas referenciais, até a etapa de elaboração das histórias em tiras de quadrinhos, houve uma apropriação espontânea, por parte dos alunos, dos conhecimentos necessários para o processo criativo de uma forma que só a arte pode fazê-lo. Os alunos foram estimulados a irem além da condição de coadjuvantes no processo de ensino-aprendizagem. Uma proposta interdisciplinar como essa é importante para que o PROEJA cumpra uma de suas missões qual seja integrar educação, ciência e cultura.

\section{REFERÊNCIAS}

André, H. A. (1982). Gramática ilustrada. 3ạ ed. São Paulo, Editora Moderna.

Brasil. (2002). Ministério da Educação. Secretaria de Educação Média e Tecnológica. Parâmetros Curriculares Nacionais: Ensino Médio. Brasília: Ministério da Educação.

Brasil. (2007). MEC/SETEC. Programa Nacional de Integração da Educação Profissional com a Educação Básica na Modalidade de Educação de Jovens e Adultos: Educação Profissional Técnica de nível Médio / Ensino Médio. Documento Base.

Centro de Pesquisa de Energia Elétrica (CEPEL). (2010). Atlas do Potencial Eólico Brasileiro Preliminar. Brasília.

CGEE - Centro de Gestão e Estudos Estratégicos. (2008). Manual de capacitação sobre mudança do clima e projetos de mecanismo de desenvolvimento limpo (MDL), Brasília - DF.

Danton, G. (2013). Como Escrever uma História em Quadrinhos. Recuperado em 15 de setembro de 2013,

http://quadrinhopole.files.wordpress.com/2013/02/comoescreverhq_giandanton.pdf

de

Edwards, B. (1979). Desenhando com o lado direito do cérebro. Rio de Janeiro, Editora Ediouro.

Eisner,W. (1989). Quadrinhos e Arte Sequencial, São Paulo: Martins Fontes.

Empresa de Pesquisa Energética, (EPE). (2012). NOTA TÉCNICA EPE - Análise da Inserção da Geração Solar na Matriz Elétrica Brasileira.

Fazenda, I. C. A. (1994). Interdisciplinaridade: história, teoria e pesquisa. 4. ed. Campinas - SP, Papirus. 
IPCC - Intergovernmental Panel on Climate Change. (2001). Summary for Policymakers. A Report of Working Group I of the Intergovernmental Panel on Climate Change. Terceiro Relatório de Avaliação do IPCC. Grupo 3. Shangai, China.

Jannuzzi, G.D., Swisher, J.N.P. (1997). Planejamento Integrado de Recursos: Meio Ambiente, Conservação de Energia e Fontes Renováveis. Editora Autores Associados. Campinas - SP, Brasil.

Macedo, I. Energia: fontes e usos finais no Brasil. São Paulo, Recuperado em 03 de setembro de 2013, de http://www.comciencia.br/reportagens/2004/12/05.shtml

Manfrinato, W. A. (1999). Mudanças Climáticas: ações e perspectivas para o novo milênio, Boletim Qualidade de Vida, CEPEA/ESALQ/USP, São Paulo, v. 1, n. 6.

Mccloud, S. (2005). Reinventando os Quadrinhos, São Paulo: M Books.

Mendonça, J.M.P. (2008). Traça Traço Quadro a Quadro, Belo Horizonte, Editora C/Arte.

Notícia Proibida. (2010). Recuperado em 02 de agosto de 2010 de http://site.noticiaproibida.org/fotos/Image/atuais/esquema_do_efeito_estufa_reduzido.jpg

Patati, C., Braga, F. (2006). Almanaque dos Quadrinhos, Rio de Janeiro, Editora Ediouro.

Rocha, M. T. (2003). Aquecimento global e o mercado de carbono: uma aplicação do modelo CERT, Piracicaba: ESALQ/USP.

Silva, E. P. Fontes renováveis de energia para o desenvolvimento sustentável. Recuperado em 08 de julho de 2013 de http://www.comciencia.br/reportagens/2004/12/15.shtml 